\title{
Respiratory training as strategy to prevent cognitive decline in aging: a randomized controlled trial
}

This article was published in the following Dove Press journal:

Clinical Interventions in Aging

20 March 2015

Number of times this article has been viewed

\author{
Leandro Ferreira' \\ Kátia Tanaka' \\ Ruth Ferreira \\ Santos-Galduróz $z^{2,3}$ \\ José Carlos \\ Fernandes Galduróz' \\ 'Department of Psychobiology, \\ Universidade Federal de São Paulo, \\ São Paulo, SP, Brazil; ${ }^{2}$ Center of \\ Mathematics, Computation and \\ Cognition, Universidade Federal do \\ $A B C$, São André, SP, Brazil; ' Institute \\ of Biosciences, Universidade Estadual \\ Paulista Júlio de Mesquita Filho, Rio \\ Claro, SP, Brazil
}

Correspondence: José Carlos Fernandes Galduróz

Department of Psychobiology, Universidade Federal de São Paulo, Rua Napoleão de Barros, 925, CEP 04024-002 São Paulo, SP, Brazil

Tel +55 II 21490168

Fax +55 II 50842793

Email galduroz@unifesp.br
Background: Inadequate oxygenation may cause lesions and brain atrophy during aging. Studies show a positive association between pulmonary function and the cognitive performance of individuals from middle age on.

Objective: To investigate the effect of aerobic physical exercises and respiratory training on the blood oxygenation, pulmonary functions, and cognition of the elderly.

Design: This was a randomized and controlled trial with three parallel groups. A total of 195 community-dwelling elderly were assessed for eligibility; only $n=102$ were included and allocated into the three groups, but after 6 months, $n=68$ were analyzed in the final sample. Participants were randomized into a social interaction group (the control group), an aerobic exercise group (the "walking" group), or a respiratory training group (the "breathing" group). The main outcome measures were the Wechsler Adult Intelligence Scale, Wechsler Memory Scale, Wisconsin Card Sorting Test, respiratory muscular strength, cirtometry (thoracicabdominal circumference); oxygen saturation in arterial blood $\left(\mathrm{SpO}_{2}\right)$, and hemogram.

Results: No differences were observed for any of the blood parameters. Aerobic exercise and respiratory training were effective in improving the pulmonary parameters. Better cognitive performance was observed for the breathing group as regards abstraction and mental flexibility. The walking group remained stable in the cognitive performance of most of the tests, except attention. The control group presented worst performance in mental manipulation of information, abstraction, mental flexibility, and attention.

Conclusion: Our results showed that both the walking and breathing groups presented improvement of pulmonary function. However, only the breathing group showed improved cognitive function (abstraction, mental flexibility). The improvement in cognitive functions cannot be explained by blood parameters, such as $\mathrm{SpO}_{2}$, erythrocytes, hemoglobin, and hematocrit.

Keywords: breathing exercises, cognition, exercise

\section{Introduction}

Studies published in recent years show a positive association between pulmonary function and cognitive performance in individuals from middle age on. ${ }^{1,2}$ This association appears to become even stronger as the individuals grow older. ${ }^{3}$ These findings suggest that the structural alterations observed in the respiratory system, ${ }^{4,5}$ modulated by a sedentary lifestyle or by pathologies, might explain the cognitive decline observed during the aging process.

In this context, the regular practice of physical exercise stands out as an accessible and highly promising intervention for the maintenance of cognitive functions. ${ }^{6}$ Previous studies have shown that the elderly present better cognitive performance after periods of systematized practice of physical exercise. ${ }^{7,8}$ High levels of physical fitness that remain 
stable appear to play a neuroprotective role against cognitive decline..$^{9,10}$ However, it is still unclear whether the improvements in cognitive functions are due to improvements in the cardiovascular system. ${ }^{11,12}$ Etnier et al $^{11}$ suggested that other physiological variables may serve to mediate the relationship between cognitive functions and exercise. This relationship could be explained by the efficiency of the respiratory system. By improving the respiratory system, physical exercise could promote better blood oxygenation and cerebral function. More accurate cognitive performance has been associated with better results in tests of pulmonary function. ${ }^{13}$

The relation between oxygen supply and cognitive function needs better characterization. Because the physiological variables that explain the connection between physical exercise and cognitive performance were not clear, the hypothesis of the present study was that physical exercise could alter the blood parameters of oxygen transport and, hence, promote improvements in cognitive performance. Additionally, we hypothesized that other techniques for training specific respiratory muscles might yield similar results to those of exercises. ${ }^{14,15}$

In contrast, the literature lacks studies that associate these respiratory exercise techniques with physiological indices of oxygen and with possible effects on cognitive functions in healthy elderly subjects. In addition to the physical exercise itself, the effectiveness of these techniques in the rehabilitation of respiratory processes might also produce positive effects on cognitive function and should, therefore, be encouraged. Specifically, in the current study we tested the hypothesis that interventions for respiratory system can: (1) improve pulmonary functions, (2) improve oxygen saturation in arterial blood $\left(\mathrm{SpO}_{2}\right)$; and (3) improve cognitive performance.

Consequently, the objective of the present study was to assess the possible effects of aerobic physical exercise and respiratory training on the blood oxygenation, pulmonary functions, and cognition of the elderly.

\section{Methods}

This was a study employing a balanced randomization, controlled, parallel-group design (Figure 1). The study protocol was approved by committee of ethics in research (UNIFESP-HSP 0129/09). The participants were recruited in the community through advertisements in the media and signed a consent form to participate. There was no racial or sex bias in the selection of participants. Each participant was assessed at baseline and post- 6 months. The neuropsychological evaluations were conducted by a researcher who was blind to participant experimental group assignment.

\section{Sample}

The final sample comprised 68 elderly individuals of both sexes. The inclusion criteria were: age between 60 and 79 years; no clinical diseases related to the respiratory system; not a user of tobacco, psychotropic drugs, or any medication that could influence cognitive performance; at least 8 years of schooling; no mild cognitive impairment or diagnosis of dementia; and not presenting limiting participation in the intervention programs proposed. Participants were randomly distributed in equal numbers (raffled by the researcher) to each of the three intervention groups.

\section{Measurements}

The evaluation comprised cognitive tests and questionnaires, and physical and laboratory investigations. The cognitive tests and questionnaires included: (1) the Mini-Mental State Examination; (2) the Wechsler Adult Intelligence Scale, subscales Digit Span, Vocabulary, Information, and Symbol Search; (3) the Wechsler Memory Scale, subscales Logic Memory I and II, and Corsi block-tapping test; (4) the Wisconsin Card Sorting Test; (5) the State-Trait Anxiety Inventory (STAI), State-Anxiety subscale; (6) the Geriatric Depression Scale (GDS); and (7) the Modified Baecke Questionnaire for the elderly (for level of physical activity). ${ }^{16}$

The physical evaluations mainly included respiratory assessments. Respiratory muscular strength was measured with a manovacuometer (maximal inspiratory pressure and maximal expiratory pressure). Cirtometry (thoracic and abdominal measurements) was performed with a measuring tape at three anatomical reference points: the axillary fold, the xiphoid process, and the umbilical scar. With the volunteers in a standing position, we took two measurements of each point, one during maximal inspiration (total lung capacity) and the other during maximal expiration (residual volume). Using those measurements, we calculated the amplitude index (AI) of each region, according to the formula:

$\mathrm{AI}(\mathrm{cm})=$ Maximal inspiration - Maximal expiration

$\mathrm{SpO}_{2}$ and heart rate at rest were also evaluated, with a pulse oximeter (after a 10-minute seated period).

Laboratory evaluations were also done. A hemogram, by automation (cytochemical/isovolumetric), was confirmed by reading of a microscope slide. The sample collections were performed in the morning ( 8 am to $10 \mathrm{am}$ ) after a nighttime fast of 10 hours. 


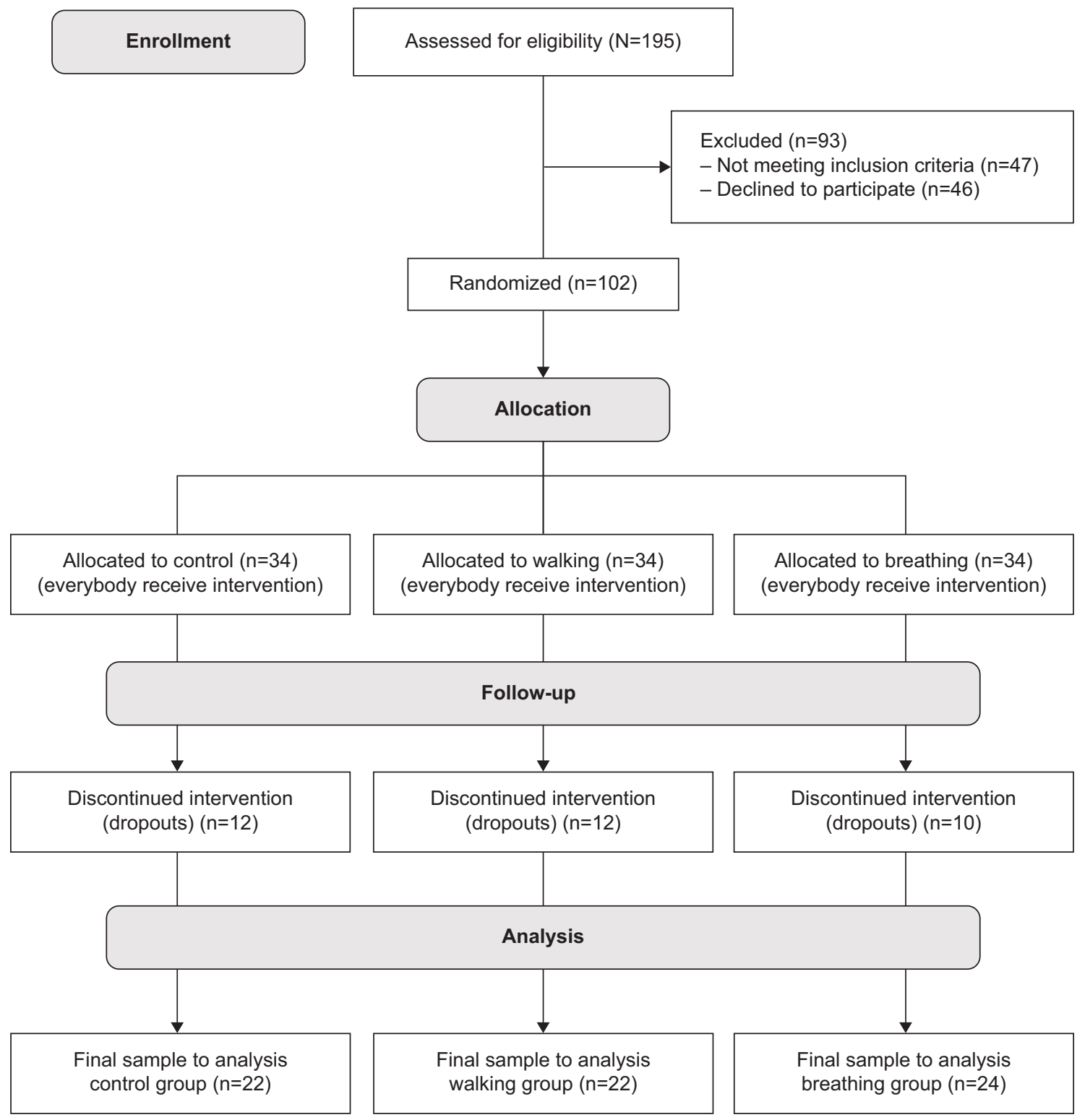

Figure I Flow diagram to assess the effects of interventions.

\section{Interventions}

\section{Aerobic exercise group (the "walking" group)}

The volunteers followed a program of supervised walking that lasted 6 months, three times a week, with duration of 40-50 minutes for each session. The intensity was controlled by a cardiac monitor and was limited to a range of $60 \%-80 \%$ of the heart rate reserve (moderate intensity).

\section{Respiratory training group (the "breathing” group)} A second experimental group followed a program of exercise that focused specifically on the respiratory system. The duration and weekly frequency were the same as for the walking group. Each session of this intervention was divided into three parts: (1) stretching exercises for the muscles of the trunk, the neck, and the upper limbs; (2) seven breathing exercises; and (3) inspiratory muscle training with a RESPIRON ${ }^{\circledR}$ (NCS Ltda, Barueri, SP, Brazil). This apparatus is a exerciser and incentive spirometry (Figure S1).

\section{Social interaction group (the control group)}

This group participated in activities involving social interaction and met at the same frequency as the intervention groups. None of the activities involved physical exercises or any specific therapy for the respiratory system.

For more details of the interventions, see the "Supplementary materials". 


\section{Data analysis}

The study consists of two independent variables, namely, groups and moment ("pre" and "post"). Therefore, multivariate analysis of variance (MANOVA) with repeated measures was used. The dependent variables were standardized by $z$-score. The general linear model (repeated measures) was used to perform the MANOVA. For main and interaction effects, the confidence interval adjustment was made by Bonferroni. The group $\times$ moment interaction from the ANOVA is presented in the "Results" section. The significance level of $P \leq 0.05$ was adopted for all statistical procedures.

\section{Results}

All the groups had a greater number of women and a similar mean for age, education, and cognitive profile (Table 1). The breathing group showed a slight increase in heart rate at rest, whereas the walking group showed a decrease. The results for the strength of the respiratory muscles showed that the breathing and walking groups exhibited improved maximal expiratory pressure. For the cirtometry, the breathing and walking groups showed improved in amplitude index in two anatomical reference points: axillary fold and umbilical scar (Table 2).

In addition to the pulmonary parameters, several blood parameters were analyzed (Table 2). No differences were observed for any of the blood parameters. Although changes in the blood parameters were not observed, performance on the cognitive tests changed significantly.

Statistical interaction was detected for semantic memory, executive functions (mental manipulation of information, abstraction, and mental flexibility), and attention as well (Table 3). In relation to semantic memory, the control group, surprisingly, showed improvement in performance. On the other hand, for mental manipulation of information, the control group showed poorer performance. In relation to abstraction, the breathing group showed improved performance,

Table I Baseline demographic and clinical characteristics for each group

\begin{tabular}{llllll}
\hline & $\begin{array}{l}\text { Control } \\
(\mathbf{n}=\mathbf{2 2})\end{array}$ & $\begin{array}{l}\text { Breathing } \\
(\mathbf{n}=\mathbf{2 4})\end{array}$ & $\begin{array}{l}\text { Walking } \\
(\mathbf{n}=\mathbf{2 2})\end{array}$ & \multicolumn{2}{c}{ ANOVA } \\
\cline { 6 - 7 } & $86.3 \%$ & $87.5 \%$ & $68.18 \%$ & & $\mathbf{P}$ \\
\hline Female & $69.2(4.8)$ & $65.9(5.2)$ & $66.2(5.6)$ & 3.03 & 0.06 \\
Age (years) & $12.9(2.5)$ & $12.5(2.9)$ & $12.9(2.7)$ & 0.13 & 0.82 \\
Education (years) & $12.1(1.5)$ & $28.8(1.6)$ & 1.42 & 0.25 \\
MMSE (score) & $28.7(1.5)$ & $28.1(2)$
\end{tabular}

Note: Values are expressed as mean (standard deviation).

Abbreviations: ANOVA, analysis of variance; MMSE, Mini-Mental State Examination.

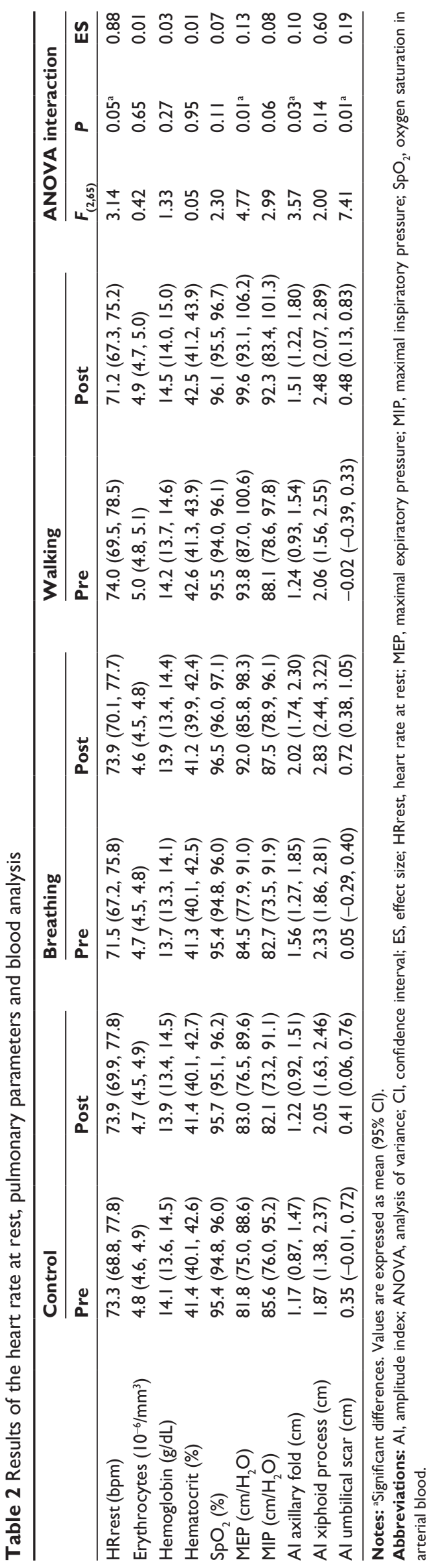




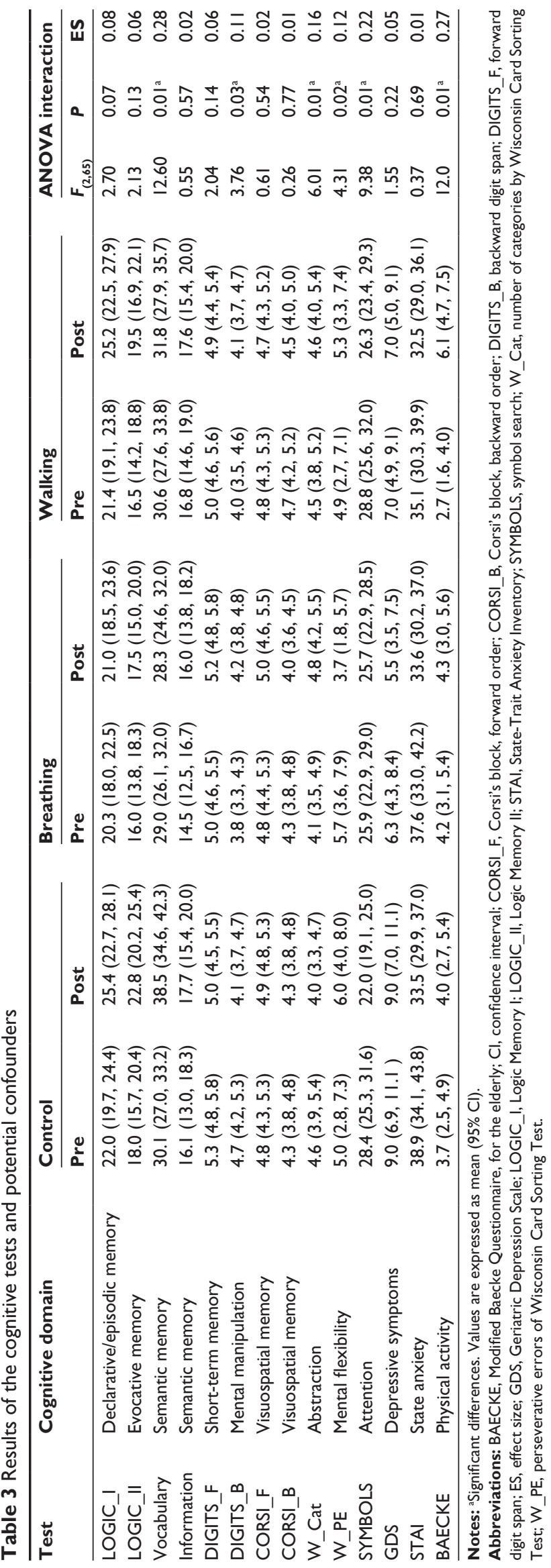

whereas the control group showed decreased performance. For mental flexibility, the breathing group showed a significant decrease in the number of perseverative errors in the test. Finally, for attention, the control and walking groups showed a slight decrease in performance, with a greater decrease in the control group.

Depressive symptoms, and state and trait anxiety were controlled, and no change was observed. The Baecke Questionnaire results showed that the control and breathing groups did not improve their physical activity level (Table 3).

\section{Discussion}

The improvement in pulmonary performance did not alter the blood parameters for oxygen transport (erythrocyte, hemoglobin, and $\mathrm{SpO}_{2}$ ). The hypothesis that those parameters could mediate the association between pulmonary function and cognitive performance was not supported.

For the blood parameters of oxygen transport, none of the elderly presented anemia (hemoglobin was $<12.0 \mathrm{pg}$ for women and $<13.0 \mathrm{pg}$ for men) at baseline or after the 6-month period. Shah et $\mathrm{al}^{17}{ }^{1}$ identified a relationship between the levels of hemoglobin and the cognitive functions of the elderly. They observed that anemia and polycythemia were associated with poorer performance in cognitive functions, particularly semantic memory and perception speed. These two conditions involving altered hemoglobin concentrations are also associated with a more rapid cognitive decline and a higher risk of Alzheimer's disease. ${ }^{18}$ Therefore, follow-up on plasma levels of hemoglobin is important for the prevention of some mental diseases. The concentration of oxygen in the blood is directly related to the amount of hemoglobin and its level of saturation in the erythrocytes. Neither of the interventions produced an increase in those parameters at rest.

Britto et a $1{ }^{19}$ reported that the elderly show lower levels of $\mathrm{SpO}_{2}$ in comparison with young adults. In the present study, all the groups showed $\mathrm{SpO}_{2}>94 \%$, levels that are considered normal for elderly subjects. ${ }^{20}$ These values may not be sufficiently low to influence cognitive performance. Studies show that cognitive impairment is associated with lower values of $\mathrm{SpO}_{2}$ than those presented by the volunteers in the present study. Cognitive impairment has been observed in adults with apnea associated with $\mathrm{SpO}_{2}$ of $81 \%$ and in patients with respiratory impairment as a result of $\mathrm{SpO}_{2}<90 \% .^{21,22}$ Those studies, however, were not conducted exclusively with elderly individuals. Therefore, it can be expected that individuals older than 60 years show a more significant cognitive impairment as a result of hypoxemia. This principle emphasizes the importance of activities that maintain $\mathrm{SpO}_{2}$ within adequate levels. 
No previous studies in the literature have associated the practice of respiratory training with the cognitive performance of the elderly. Respiratory exercises consist of activities that require attention to the instructions and mental planning to perform the sequence of exercises proposed. This aspect of the intervention may be the fundamental reason for the greater effectiveness in the improvement of the cognitive function. Respiratory exercises are considered a nonpharmacological technique for the promotion of sleep. ${ }^{23}$ This effect could also constitute an indirect mechanism through which the elderly in the breathing group improved their cognitive performance. This relationship should be further investigated in future studies.

Mental stimulation and social interaction are also important variables in the maintenance of cognitive functions during aging. For this reason, the control group participated in activities involving social interaction. Vance et a ${ }^{24}$ proposed the "hypothesis of social stimulation" produced by group activities as one of the main factors that enhance cognitive functions. Nevertheless, the social interaction group in the present study showed a decrease in cognitive functions and attention and showed improvement only in semantic memory. The multimodal aspect of the activities the control group might explain this result. Perform several different activities can lead at general benefits in cognition but show little effects for some specific parameters of cognitive functions. ${ }^{25}$ In the other side, specific training produces substantial general benefits and good transfer effects, even for aspects of the executive functions that were not stimulated. ${ }^{26}$

The cognition results for the group that performed aerobic exercises contradicts other studies reported in the literature that detected better cognitive performance after the practice of systematized physical exercises. ${ }^{7,8,13}$ On the other hand, they confirm a previous systematic review that questions whether the aerobic training component is necessary for improvements in cognitive function. ${ }^{12}$ Other types of physical exercise or interventions can find better results. The prefrontal cortex appears to be more sensitive to the effects of aging; therefore physical exercise has been found to promote greater benefits for the executive functions than for the other cognitive parameters. ${ }^{6,27}$ However, this improvement in the executive functions was not observed in the present study. Our results corroborate those of a systematic review that did not find any effect in the majority of the studies among subjects without cognitive decline after exercise programs. ${ }^{28}$

It is noteworthy that each type of physical exercise appears to produce distinct effects on cognition. ${ }^{6,12}$ Özkaya et al ${ }^{29}$ used the same prescription of aerobic exercise (walking) used in the present study and observed only slight cognitive alterations relative to the control group. Moreover, those researchers observed that strength training yielded more significant effects on cognitive functions than did walking. According to van Uffelen et al ${ }^{28}$ the large variability in exercise programs, sample characteristics, and outcome measures hamper comparisons between studies.

In general, aerobic exercise and respiratory training helped to maintain or improve the parameters of cognitive functions of the elderly. This result is significant because a cognitive decline is expected in elderly individuals. ${ }^{30}$ Elderly individuals who show a decline in cognitive capacity might display a stable and benign trajectory, but this decline might represent an incipient dementia in certain cases..$^{31}$ The maintenance of cognitive functions is also fundamental because it reduces the risks of death and functional incapacity in the elderly. ${ }^{32}$

Factors that can influence cognitive performance were also controlled, and no interference was detected. None of the groups presented depressive symptoms (GDS $>10$ points) or high levels of anxiety (STAI $>50$ ) at baseline. Generally, one of the main benefits of physical and respiratory exercises is the effect of these exercises on the factors that modulate cognitive performance, such as anxiety and depression. ${ }^{15,24}$ Participation in the activities of the study might have contributed to the maintenance of the baseline condition of the elderly.

Finally, the interventions used yielded positive results for the pulmonary and cognitive functions of the elderly. Future studies could investigate the levels of oxygenation during and after each of the activities performed. Additionally, the effects of the interventions used in the present study might be different for more specific samples, eg, elderly individuals with hypoxemia or anemia. Different results might also be observed after the combined practice of aerobic exercise and respiratory training.

\section{Strengths and limitations}

The strengths and weaknesses of this research are worth noting. On the positive side, the present study was a longitudinal randomized trial in which interventions were monitored and supervised. The interventions suggested in this study can be offered by the departments of public health because they are easy, affordable, and have low cost. Stimulating preventive behaviors must be the key role of health professionals. The present study is original in that it measured respiratory pressure and the thoracic-abdominal circumference. Further, it assessed the effects of respiratory training on cognitive performance. On the other hand, it has some 
limitations. The measurement of blood oxygenation at rest may not represent the potential benefits of interventions for the elderly. These interventions may have provided greater $\mathrm{SpO}_{2}$ during the performance of activities, and this benefit may be extended for a certain time after the end of the activities. Other measurements of $\mathrm{SpO}_{2}$ could have been performed throughout the day. The benefits of exercise may have been limited by the intensity-based prediction of maximal heart rate and not directly measured in a laboratory test. Although the formulas for predicting maximal heart rate have good correlation with that measured by the maximal heart rate in test, direct determination is even more effective. Finally, all groups had dropouts, and the final sample was not as large. Using a larger sample size could yield significant differences in other variables (eg, age and episodic memory). Nevertheless, future large-scale studies might also confirm the present results.

\section{Conclusion}

Aerobic exercise and respiratory training improved the pulmonary function of the volunteers. No alterations were detected in the $\mathrm{SpO}_{2}$. Respiratory training improved specific cognitive parameters, such as executive functions and attention. The activities that involved only social interaction (control group) improved only semantic memory.

\section{Acknowledgments}

We thank the following agencies and institutions for their funding of our research: National Council for Scientific and Technological Development (Conselho Nacional de Desenvolvimento Científico e Tecnológico - CNPq/Brasil), São Paulo Research Foundation (Fundação de Amparo à Pesquisa do Estado de São Paulo), and Research Incentive Fund Association (Associação Fundo de Incentivo à Pesquisa).

\section{Disclosure}

The funding agencies had no role in study design, data collection, analysis and interpretation of data, writing of the report, or the decision to submit the report for publication. The authors report no conflicts of interest in this work.

\section{References}

1. Pathan SS, Gottesman RF, Mosley TH, Knopman DS, Sharrett AR, Alonso A. Association of lung function with cognitive decline and dementia: the Atherosclerosis Risk in Communities (ARIC) Study. Eur J Neurol. 2011;18(6):888-898.

2. Singh-Manoux A, Dugravot A, Kauffmann F, et al. Association of lung function with physical, mental and cognitive function in early old age. Age (Dordr). 2011;33(3):385-392.

3. Anstey KJ, Windsor TD, Jorm AF, Christensen H, Rodgers B. Association of pulmonary function with cognitive performance in early, middle and late adulthood. Gerontology. 2004;50(4):230-234.
4. Zaugg M, Lucchinetti E. Respiratory function in the elderly. Anesthesiol Clin North America. 2000;18(1):47-58.

5. Sharma G, Goodwin J. Effect of aging on respiratory system physiology and immunology. Clin Interv Aging. 2006;1(3):253-260.

6. Colcombe S, Kramer AF. Fitness effects on the cognitive function of older adults: a meta-analytic study. Psychol Sci. 2003;14(2):125-130.

7. Cassilhas RC, Viana VA, Grassmann V, et al. The impact of resistance exercise on the cognitive function of the elderly. Med Sci Sports Exerc. 2007;39(8):1401-1407.

8. Ruscheweyh R, Willemer C, Krüger K, et al. A physical activity and memory functions: an interventional study. Neurobiol Aging. 2011; 32(7):1304-1319.

9. Barnes DE, Yaffe K, Satariano WA, Tager IB. A longitudinal study of cardiorespiratory fitness and cognitive function in healthy older adults. $J$ Am Geriatr Soc. 2003;51(4):459-465.

10. Dishman RK, Berthoud H, Booth FW, et al. Neurobiology of exercise. Obesity (Silver Spring). 2006;14(3):345-356.

11. Etnier JL, Nowell PM, Landers DM, Sibley BA. A meta-regression to examine the relationship between aerobic fitness and cognitive performance. Brain Res Rev. 2006;52(1):119-130.

12. Angevaren M, Aufdemkampe G, Verhaar HJ, Aleman A, Vanhees L. Physical activity and enhanced fitness to improve cognitive function in older people without known cognitive impairment. Cochrane Database Syst Rev. 2008;2:CD005381.

13. Kara B, Pinar L, Uğur F, Oğuz M. Correlations between aerobic capacity, pulmonary and cognitive functioning in the older women. Int J Sports Med. 2005;26(3):220-224.

14. Kunikoshita LN, Silva YP, Silva TLP, Costa D, Jamami M. [Effects of three respiratory physical therapy programs on patients with COPD]. Rev Bras Fisioter. 2006;10(4):449-455. Portuguese.

15. Kjellgren A, Bood SA, Axelsson K, Norlander T, Saatcioglu F. Wellness through a comprehensive yogic breathing program - A controlled pilot trial. BMC Complement Altern Med. 2007;7:43.

16. Voorrips LE, Ravelli AC, Dongelmans PC, Deurenberg P, Van Staveren WA. A physical activity questionnaire for elderly. Med Sci Sports Exerc. 1991;23(8):974-979.

17. Shah RC, Wilson RS, Tang Y, Dong X, Murray A, Bennett DA. Relation of hemoglobin to level of cognitive function in older persons. Neuroepidemiology. 2009;32(1):40-46.

18. Shah RC, Buchman AS, Wilson RS, Leurgans SE, Bennett DA. Hemoglobin level in older persons and incident Alzheimer disease: prospective cohort analysis. Neurology. 2011;77(3):219-226.

19. Britto RR, Zampa CC, de Oliveira TA, Prado LF, Parreira VF. Effects of the aging process on respiratory function. Gerontology. 2009; 55(5):505-510.

20. Van de Louw A, Cracco C, Cerf C, et al. Accuracy of pulse oximetry in the intensive care unit. Intensive Care Med. 2001;27(10):1606-1613.

21. Findley LJ, Barth JT, Powers DC, Wilhoit SC, Boyd DG, Suratt PM. Cognitive impairment in patients with obstructive sleep apnea and associated hypoxemia. Chest. 1986;90(5):686-690.

22. Hopkins RO, Weaver LK, Pope D, Orme JF, Bigler ED, Larson-LOHR V. Neuropsychological sequelae and impaired health status in survivors of severe acute respiratory distress syndrome. Am J Respir Crit Care Med. 1999;160(1):50-56.

23. Cole RJ. Nonpharmacologic techniques for promoting sleep. Clin Sports Med. 2005;24(2):343-353.

24. Vance DE, Wadley VG, Ball KK, Roenker DL, Rizzo M. The effects of physical activity and sedentary behavior on cognitive health in older adults. J Aging Phys Act. 2005;13(3):294-313.

25. Lusting C, Shah P, Seidler R, Reuter-Lorenz PA. Aging, training, and the brain: a review and future directions. Neuropsychol Rev. 2009;19(4): 504-522.

26. Anand R, Chapman SB, Rackley A, Keebler M, Zientz J, Hart J. Gist reasoning training in cognitively normal seniors. Int $J$ Geriatr Psychiatry. 2011;26(9):961-968.

27. Tisserand DJ, Jolles J. On the involvement of prefrontal networks in cognitive ageing. Cortex. 2013;39(4-5):1107-1128. 
28. van Uffelen JG, Chin A, Paw MJ, Hopman-Rock M, van Mechelen W. The effects of exercise on cognition in older adults with and without cognitive decline: a systematic review. Clin J Sport Med. 2008;18(6): 486-500.

29. Özkaya GY, Aydin H, Toraman FN, Kizilay F, Ozdemir O, Cetinkaya V. Effect of strength and endurance training on cognition in older people. J Sports Sci Med. 2005;4(3):300-313.

30. Rabbitt P, Diggle P, Holland F, McInnes L. Practice and drop-out effects during a 17-year longitudinal study of cognitive aging. J Gerontol B Psychol Sci Soc Sci. 2004;59(2):P84-P97.
31. Charchat-Fichman H, Caramelli P, Sameshima K, Nitrini R. [Decline of cognitive capacity during aging]. Rev Bras Psiquiatr. 2005;27(1):79-82. Portuguese.

32. Yaffe K, Lindquist K, Vittinghoff E, et al; Health, Aging and Body Composition Study. The effect of maintaining cognition on risk of disability and death. J Am Geriatr Soc. 2010;58(5):889-894. 


\section{Supplementary materials \\ Details of the interventions}

\section{Aerobic exercise group (the "walking" group)}

The maximal heart rate $\left(\mathrm{HR}_{\max }\right)$ was estimated with the equation:

$$
\mathrm{HR}_{\text {max }}=220-\text { age }
$$

the heart rate reserve (HRR) was calculated from the heart rate at rest $\left(\mathrm{HR}_{\text {rest }}\right)$, using the equation:

$$
\mathrm{HRR}=\mathrm{HR}_{\max }-\mathrm{HR}_{\text {rest }}
$$

The training intensity was calculated with the equation:

$$
\text { Intensity }=\% \text { of target intensity }\left(\mathrm{HR}_{\max }-\mathrm{HR}_{\text {rest }}\right)+\mathrm{HR}_{\text {rest }}
$$

The intensity was adjusted at the beginning of each month, and the volunteers followed the following training schedule: 2 months at their own chosen of intensity (adaptation), 2 months at $60 \%-70 \%$ of HRR, and 2 months at $70 \%-80 \%$ HRR. The program was performed in two public parks. The parks are safe, clean, well-wooded, and have appropriate space to practice physical exercises.

\section{Respiratory training group (the "breathing” group)}

The breathing exercises were performed sitting in a comfortable upright position with spine straight. For each session, seven exercises were chosen from the list below.

1. "Low" breathing (abdominal or diaphragm breathing): While sitting, maximum inspiration was taken through the nose, while relaxing the abdomen; after, maximal inspiration was taken while contracting the abdomen.

2. "High" breathing ("clavicular breathing"): While sitting, the abdomen was kept contracted; in this position, a breath was taken through the nose, filling and emptying the chest only (The breathing in this position is difficult and short).

3. "Middle" breathing: While sitting, the abdomen was lightly constricted, and then, a breath was taken through the nose mainly, with expanding of the middle region of the trunk (position of eighth to 12th ribs); after, the breath was slowly released.

4. "Alternate" breathing: While sitting, inhalation was done through both nostrils, with exhalation through the left nostril and right nostril, alternately. Blockage of the nostrils on the exhale was done alternately with the index finger and thumb of the hand of preference.
5. "Bellows" breathing: While sitting, with mouth gently closed, breathing in and out of the nose was done as fast as possible. This exercise could be performed with low, middle, or high breathing.

6. "Hara" breathing: While sitting, slow inspiration was done through the nose followed by a pause; then the breath was exhaled with the mouth open (pronouncing "fffff..."). The abdomen remained relaxed and returned to starting position to the end of expiration.

7. "Yawn" breathing: While sitting, a maximal inspiration was followed by expiration with mouth open, with the pronouncement of the vowel "a" (yawning)

8. "Blow the soup" breathing: While sitting, maximal inspiration was done through the nose, followed by expiration with mouth beak-shaped, as if blowing on soup. Variation: A maximal expiration was performed while simultaneously contracting the abdomen.

9. "Blow the candle" breathing: While sitting in front of a lit candle, maximal inspiration was done through the nose, followed by exhalation with mouth beak-shaped, blowing the candle flame just enough to bend it, without extinguishing it. Variation: The candle was placed at different distances, requiring greater control of expiratory flow. Slow expiration was performed while simultaneously contracting the abdomen.

10. "Lateral" breathing: While sitting, the left hand was placed on the right ribs; Inspiration was performed while tilting the torso to the left and extending the right arm straight over the head (the participant was instructed to "Feel the pressure" in the ribs under the left hand). This was followed by the return to starting position, with expiration. The same exercise was repeated for the opposite side.

11. Strong contraction of the abdomen: While standing, the participant slightly inclined the trunk forward and rested hands on semiflexed knees. A maximum expiration was done, followed by strong contraction of the abdomen and elevation of the diaphragm. This position was held for a few seconds, followed by inspiration and relaxation of the abdomen.

12. "Blocking" breathing: While sitting, a maximal inspiration was followed by a pause in breathing. The epiglottis was held closed, with head tilted, for as long as possible.

13. Oscillation of the trunk: While sitting, a maximum inspiration was followed by a pause. With bated breath, the chest and abdomen were alternately contracted and 


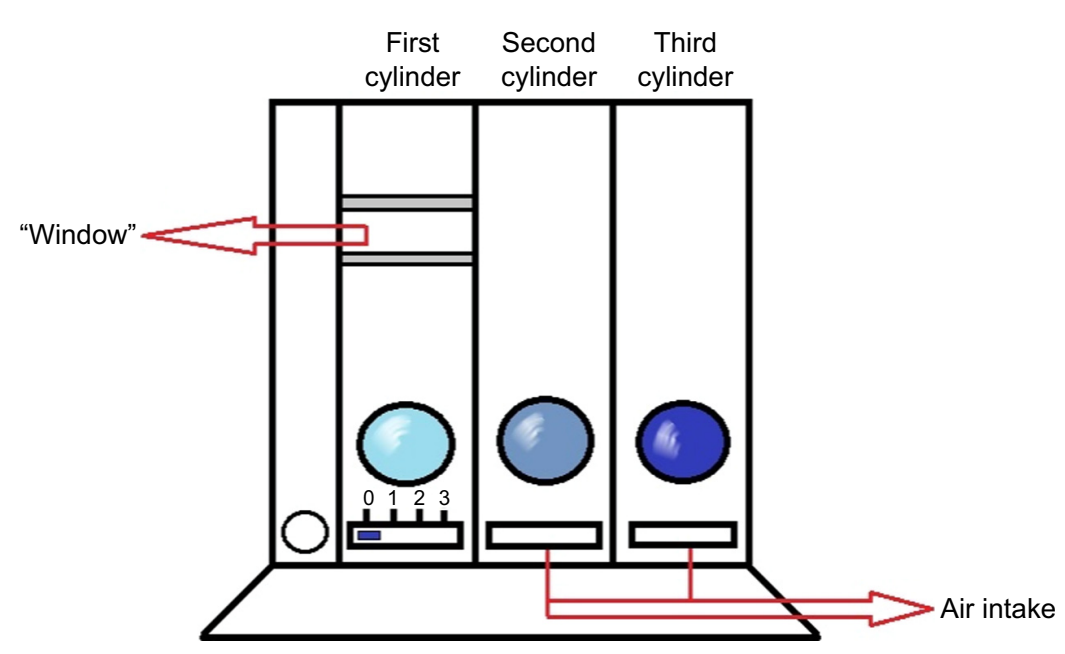

Figure SI Illustration of the exerciser and incentive spirometry

Note: Adapted with permission from the product manual (RESPIRON ${ }^{\circledR}$; NCS Ltda, Barueri, SP, Brazil).'

expanded, for a certain time, followed by a maximum expiration.

14. Pulmonary stimulation: While sitting, a maximum inspiration was followed by a pause. With bated breath, the chest was lightly slapped. Further inspiration was attempted, then the air was released through exhalation.

15. Breath expansion: While sitting, inspiration and expiration was done without pause. The same exercise was performed with one pause and then, with two pauses. Three pauses were attempted. The aim was to fractionate the breath with the pause and promote further expansion of the chest. Variation: At every pause, the breath was held and the abdomen was contracted one to three times.

16. "Jug" breathing: While sitting, one hand was placed on the abdomen and the other on the chest. Inspiration was done "by filling" the abdomen and then the chest. The expiration emptied the air first from the chest, then the abdomen.

17. "Semiblocked" breathing: While sitting, one nostril was blocked. Slow inhalation and exhalation was done through one nostril, followed by repeat with the other nostril.

18. "Fractionated" breathing: While sitting, breaths were taken in "small portions" (fractional) to the maximum filling of the lungs, followed by exhalation in small portions until complete emptying. The abdomen was simultaneously contracted with each exhalation.

19. "Total awareness" exercise: While sitting, breathing was done through the nose, by "filling the abdomen"; in the maximal pulmonary capacity the breath was blocked and then, the abdomen was contracted. After a pause, exhalation was done through the mouth with further contraction of the abdomen. At the end of exhalation, the abdomen was relaxed.

20. "Emptying the lungs": While sitting, full exhalation was done through the mouth with simultaneous contraction of the abdomen. The breath was held and head tilted, and this position was maintained as long as possible. This was followed by a strong inspiration through the nose, while lifting the head and relaxing the abdomen.

\begin{tabular}{|c|c|}
\hline \multirow[t]{2}{*}{ Exercise 1} & Raise the ball of the first cylinder to the top \\
\hline & Note: In case of failure in this task follow for "Extra instruction" \\
\hline Exercise 2 & Raise the ball of the first cylinder to the top and keep it as long as possible \\
\hline Exercise 3 & Raise the ball of the first cylinder to the "window" and keep it as long as possible \\
\hline Exercise 4 & $\begin{array}{l}\text { Raise the ball of the second cylinder to the half of the height and keep it as long as } \\
\text { possible }\end{array}$ \\
\hline Exercise 5 & Raise the ball of the second cylinder to the top and keep it as long as possible \\
\hline Exercise 6 & Raise the ball of the third cylinder to the top and keep it as long as possible \\
\hline
\end{tabular}

Figure S2 Instructions for use of the RESPIRON ${ }^{\circledR}$ (NCS Ltda, Barueri, SP, Brazil).

Notes: Extra instruction: Put adhesive labels on the air intake of cylinders 2 and 3 (front and back). Perform exercises I-3. Then, remove the adhesive labels and perform exercises $\mathrm{I}-6$, at level 0 . 
In the third part of session, the volunteers performed inspiratory muscle training using the RESPIRON ${ }^{\circledR}$ device (NCS Ltda, Barueri, SP, Brazil). This apparatus promotes resistance to the flow of inspired air. It consists of three cylinders that house balls (Figure S1). With inhalation through the mouthpiece, the balls rise as result of the effort (visual incentive). The respiratory training was conducted in a large, airy and quiet room. The volunteers performed the exercises sitting in a chair without arms.

Figure S2 shows the instructions for use of the RESPIRON ${ }^{\circledR}$. The exercises started at level "zero" (adjustment in the base of the first cylinder). After completing the exercises 1-6 at level 0 , the level was changed to level 1 and the exercises performed again and so on, until level 3 was completed.

\section{Social interaction group (the control group)}

The participants performed activities such as painting, knitting, art with material recycled, tapestry, marquetry, embroidery, and origami. Each volunteer participated in three different activities per week. The activities were performed in a public senior living center.

\section{Reference}

1. RESPIRON ${ }^{\circledR}$ [Instruction Manual]. Barueri: NCS Indústria e Comércio de Equipamentos para Saúde, Ltda; 1997. Brazil.
Clinical Interventions in Aging

\section{Publish your work in this journal}

Clinical Interventions in Aging is an international, peer-reviewed journal focusing on evidence-based reports on the value or lack thereof of treatments intended to prevent or delay the onset of maladaptive correlates of aging in human beings. This journal is indexed on PubMed Central, MedLine,

\section{Dovepress}

CAS, Scopus and the Elsevier Bibliographic databases. The manuscript management system is completely online and includes a very quick and fair peer-review system, which is all easy to use. Visit http://www.dovepress. $\mathrm{com} /$ testimonials.php to read real quotes from published authors. 